STUDI

FRANCESI

\section{Studi Francesi}

Rivista quadrimestrale fondata da Franco Simone

166 (I | LVI) | 2012

Varia

\title{
Jean-Luc Mattéoli, L'Objet pauvre. Mémoire et quotidien sur les scènes contemporaines françaises
}

\section{Paola Perazzolo}

\section{(2) OpenEdition}

\section{Journals}

\section{Edizione digitale}

URL: https://journals.openedition.org/studifrancesi/4823

DOI: $10.4000 /$ studifrancesi.4823

ISSN: 2421-5856

\section{Editore}

Rosenberg \& Sellier

\section{Edizione cartacea}

Data di pubblicazione: 1 avril 2012

Paginazione: 188

ISSN: 0039-2944

\section{Notizia bibliografica digitale}

Paola Perazzolo, «Jean-Luc Mattéoli, L'Objet pauvre. Mémoire et quotidien sur les scènes contemporaines françaises», Studi Francesi [Online], 166 (I | LVI) | 2012, online dal 30 novembre 2015, consultato il 19 novembre 2021. URL: http://journals.openedition.org/studifrancesi/4823 ; DOI: https://doi.org/ 10.4000/studifrancesi.4823

Questo documento è stato generato automaticamente il 19 novembre 2021.

\section{(c)}

Studi Francesi è distribuita con Licenza Creative Commons Attribuzione - Non commerciale - Non opere derivate 4.0 Internazionale. 


\title{
Jean-Luc Mattéoli, L'Objet pauvre. Mémoire et quotidien sur les scènes contemporaines françaises
}

\author{
Paola Perazzolo
}

\section{NOTIZIA}

JEAN-LUC MATTÉOLI, L'Objet pauvre. Mémoire et quotidien sur les scènes contemporaines françaises, Rennes, Presses Universitaires de Rennes, 2011 («Le Spectaculaire»), pp. 254.

1 Tratto da una tesi discussa nel 2006, il volume si propone di analizzare presenze, forme, significati dell'oggetto povero (cioè marginale e recuperato o quotidiano e pertanto insignificante, come teorizzato da vari artisti del secolo scorso, da Picasso fino al movimento italiano dell'Arte Povera) messo in scena nelle creazioni di compagnie contemporanee quali Théâtrenciel, Théâtre de Cuisine, 26.000 couverts, DeschampsMakeïeff, Théâtre du Radeau, per non citarne che alcune. Benché caratterizzate da pratiche ed estetiche diverse (teatro di strada o "regolare", spettacoli di marionette), tutte queste troupes incentrano il lavoro teatrale su quello che per T. Kantor costituiva non un accessorio ma un vero e proprio partner dell'attore, in grado di restituire il reale. Sia esso estratto dallo spazio urbano, recuperato per strada, da Emmaus o nelle brocantes nel corso di pigre flâneries - e per ciò antitetico all'ideologia consumistica e alla logica lavorativa contemporanea-oppure nuovo e successivamente defunzionalizzato attraverso modifiche, assemblaggi, collages o metaforizzazioni, l'oggetto strappato alla sua marginalità risulta sempre investito del compito di esprimere, alla fine di un secolo profondamente tragico e segnato da una forte disumanizzazione, quel «sens de l'humain» che per Aristotele è consustanziale alla tragedia.

Protagonista di un «jeu équivoque du temps, de l'histoire, de la mémoire et de la mort» (p. 69) per il suo valore umano di resto, di memoria, di rovina, per il suo essere un «témoin de la disparition des êtres et des choses, vécue sur le mode de la perte» 
(p. 244), grazie alla sua (in)significanza l'oggetto povero si pone come résistant, come «objecteur» sia a livello ideologico («Dans une société qui aujourd'hui fonctionne selon le schéma brutal de 'production/tri/déchet', la réponse à cette désespérance, c'est que les objets deviennent des acteurs de fiction», affermava nel 2005 Macha Makeïeff, cit. a p. 127) che sul piano teatrale, favorendo modalità di recitazione e (rap)presentazione che rimettano in discussione assunti tradizionali quali la spettacolarità del mondo e del teatro o il ruolo centrale del testo e dell'attore. Lungi dall'essere padrone (quasi) assoluto della scena, talvolta ridotto al ruolo di actant, l'attore dialoga in modo inedito con un testimone inerte. La presenza di quest'ultimo modifica gli usi scenici permettendo al contempo l'espressione di estetiche differenti (che l'A. definisce come «populaires» e «du quotidien») attraverso la ripresa di dispositivi propri alla festa popolare e alla fiera, la rivalutazione di figure dimenticate come quella del conteur e l'esplicitazione del ridicolo o del sublime di un quotidiano che propone una grazia dell'informe passibile, come accade nelle produzioni del Théâtre du Radeau, di «mettre à l'épreuve l'ensemble du fait théâtral, depuis les acteurs jusqu'aux spectateurs en passant par les textes et les lumières» (p. 237).

Ben scritto e documentato, il volume tratta in modo intelligente e puntuale un argomento originale e poco affrontato, mostrando come l'adesione alla poetica dell'oggetto povero permetta non solo di rinnovare i canoni tradizionali dell'estetica teatrale ma anche di esprimere appieno una modernità diffratta e tragica, come affermava provocatoriamente un secolo fa Schwitters, sostenitore dell'uso artistico dell'oggetto recuperato per cui «seul le mauvais matériau, utilisé de la mauvaise manière, vous donnera le bon tableau, en le regardant sous le bon angle. Ou le mauvais angle» (cit. a p. 16). 